\title{
TYROSINASE INHIBITORY AND ANTIOXIDANT ACTIVITY OF WILD ROSA CANINA L. AND SORBUS AUCUPARIA L. FRUIT EXTRACTS
}

\author{
MILICA I. STANKOVIĆ'*, VESNA LJ. SAVIĆ', JELENA V. ŽIVKOVIĆ', \\ LJILJANA P. STANOJEVIĆ ${ }^{2}$, VANJA M. TADIĆ ${ }^{3}$ and IVANA A. ARSIĆ ${ }^{1}$
}

${ }^{1}$ University of Niš, Faculty of Medicine, Department of Pharmacy, 81 Blvd. 18000 Niš, Serbia

${ }^{2}$ University of Niš, Faculty of Technology, Department of Chemistry and Chemical Technology, 124 Blvd. Oslobodjenja, 16000 Leskovac, Serbia

${ }^{3}$ Institute for Medicinal Plant Research "Dr Josif Pančić", Department for Pharmaceutical Research and Development, 1 Tadeuša Košćuška, 11000 Belgrade, Serbia

\begin{abstract}
In the present work, fruits from two plant species, Rosa canina L. and Sorbus aucuparia L., popular in traditional folk medicine in Serbia, were studied. The aim was to examine and compare the efficiency of the ultrasonic extraction with different solvents regarding physicochemical properties, polyphenolic profile of extracts, as well as their tyrosinase inhibitory and antioxidant activity. The polyphenols evaluation indicated that water was the best solvent for a thorough extraction of bioactive compounds from the $R$. canina fruits, while propylene glycol-water (45:55, v/v) was the most efficient regarding $S$. aucuparia fruits, followed by ethanol-water $(7: 3, \mathrm{v} / \mathrm{v})$. Only flavonoids were more abundant in $S$. aucuparia fruit extracts. $R$. canina water extracts showed higher antioxidant activity, using several in vitro tests with different working principles. However, S. aucuparia ultrasonic extracts with propylene glycol-water (45:55, v/v) demonstrated a higher potential concerning tyrosinase inhibitory and chelating activity. Therefore, these ultrasonic extracts, being great sources of natural anti-tyrosinase inhibitors and antioxidants, can be considered as promising candidates suitable for pharmaceutical application, as great sources of natural anti-tyrosinase inhibitors and antioxidants.
\end{abstract}

Keywords: Rosa canina L., Sorbus aucuparia L., anti-tyrosinase, antioxidants, polyphenols

Utilization of plant fruits rich in antioxidants and other phytonutrients can prevent and control many diseases $(1,2)$. Due to the decreasing usage of synthetic antioxidants over the past decade, herbs and plants have been widely considered as alternative sources for extraction of natural phenol-based antioxidants, both individual and those present in extracts, which are more acceptable than the synthetic ones. Tyrosinase is a copper-containing enzyme that is essential in the melanin biosynthesis. Nothing less important is the use of naturally derived tyrosinase inhibitors in melanogenesis disorders, skin hyperpigmentations and other melaninrelated problems (3). Since well-known tyrosinase inhibitors (hydroquinone, arbutin, kojic acid) are associated with various adverse effects (4), it is a challenge to find inhibitors from natural sources for practical use in industry.

Rosa canina L. and Sorbus aucuparia L., which both belong to the Rosaceae family, are pop- ular in traditional folk medicine in Serbia for the treatment of various disorders. Geographic variation and environmental conditions significantly affect plants' bioactive chemicals composition and their antioxidant activity. Namely, our country has a unique biodiversity of fruit species, which possess excellent quality and high nutritive value for usage in the human diet (5). Ethno-botanical usage of $R$. canina and $S$. aucuparia fruits is mostly for preparing jelly, jams, tea, alcoholic beverages, and other products. $R$. canina or dog rose has characteristic rose hips, pseudo-fruits or false fruits which contain a wide variety of bioactive constituents (68). It is especially rich in ascorbic acid and used in the treatment of cold, vitamin C deficiency, flu, but also for diabetes, chronic pain, some gastrointestinal and kidney disorders and for skin care. S. aucuparia (mountain ash, rowanberry) is widely spread as a decorative and medicinal plant in Europe. Due to its anti-inflammatory, diuretic, vasoprotective and

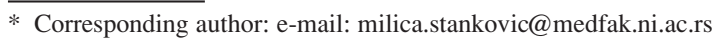


vasorelaxant properties, it has been used in the treatment of diabetes, intestinal obstructions, bronchospasm, chronic diarrhea, liver and gallbladder diseases $(9,10)$. Most of the previous studies were concerned with the testing of $S$. aucuparia inflorescences and leaves or fruits from the plant cultivars and different Sorbus genotypes $(11,12)$.

However, there is scarce information available on in vitro tyrosinase inhibitory and chelating activity of $R$. canina and $S$. aucuparia fruits and their extracts. Also, previous studies emphasized that antioxidant potential and phenolic content are significantly affected by the extraction method and the solvent used for the raw plant material extraction (13). Consequently, the aim of the present study was to examine and compare the efficiency of ultrasonic extraction with different solvents regarding physicochemical properties, polyphenolic profile, as well as anti-tyrosinase and antioxidant activities of wild fruit extracts from $R$. canina and $S$. aucuparia originating from Serbia. Antioxidant activity of extracts was evaluated by several in vitro techniques, such as radical scavenging assays against $\mathrm{DPPH}$, nitric oxide and hydroxyl radicals, FRAP assay, assay of inhibition of $\beta$-carotene bleaching and metal-chelating activity.

\section{EXPERIMENTAL}

\section{Plant material}

Fruits of Rosa canina L. and Sorbus aucuparia L. were collected in the late September 2015, from plants growing wild on the locality of Vlasina National Park, Serbia. The plant material was identified and the voucher specimens were deposited at the herbarium of the Institute for Medicinal Plant Research "Dr Josif Pančić", Serbia (Nº. 2008RC and $\mathrm{N}^{\mathrm{O}}$. 1407SA, for $R$. canina and $S$. aucuparia, respectively). The fruits were harvested at the biologically ripe stage, randomly, from different parts of the plants and stored at $-20^{\circ} \mathrm{C}$ until analyzed.

\section{Chemicals and reagents}

Folin-Ciocalteu reagent, hide powder, sodium nitroprusside, pyrogallol, catechin, ethylenediaminetetraacetic acid (EDTA), mannitol, L-ascorbic acid, 2,2-diphenyl-1-picrylhydrazyl (DPPH), 2,4,6tris-(2-pyridyl)-s-triazine (TPTZ), $\beta$-carotene, linoleic acid, Tween 20 (polyoxyethylenesorbitan monolaurate), dimethyl sulfoxide (DMSO), L-3,4dihydroxyphenyl-alanine (L-DOPA), kojic acid, 3(2-pyridyl)-5,6-diphenyl-1,2,4-triazine-p,p'-disulfonic acid monosodium salt hydrate (ferrozine) and methanol were purchased from Sigma-Aldrich
(Germany). Tyrosinase from mushroom was also the product of Sigma-Aldrich (Germany). The specific activity of the enzyme was 5771 units/mg. Griess reagent, gallic acid, rutin trihydrate and ethylenediaminetetraacetic acid disodium salt dihydrate $\left(\mathrm{Na}_{2}\right.$ EDTA $\left.\times 2 \mathrm{H}_{2} \mathrm{O}\right)$ were from Fluka Analytical (Switzerland). Vanillin and 2-deoxy-2ribose were purchased from Carl Roth (Germany). Thiobarbituric acid (TBA) was obtained from abcr GmbH (Germany). 3,5-Di-tert-4-butylhydroxytoluene (BHT) was purchased from Supelco Analytical (USA), 6-hydroxy-2,5,7,8-tetramethylchroman-2carboxylic acid (Trolox) from Acros Organics (Denmark) and chloroform from VWR International (USA). All the other chemicals, which were obtained from Centrohem (Serbia), and solvents used were of analytical grade. Freshly distilled water was used in all experiments.

\section{Preparation of extracts and evaluation of physic- ochemical properties}

Fifty grams of the fruits were extracted with four different solvents ( $\mathrm{D}: \mathrm{E}=1: 5$, w/w), including methanol (methanolic extracts - MEs), ethanolwater $(7: 3, \mathrm{v} / \mathrm{v})$ (ethanolic extracts - EEs), propylene glycol-water $(45: 55, \mathrm{v} / \mathrm{v})$ (propylene glycolic extracts - PEs) and water (water extracts - WEs) in an ultrasonic bath (power $160 \mathrm{~W}$, frequency 40 $\mathrm{kHz}$ ), operating at temperature $22 \pm 1^{\circ} \mathrm{C}$, during 30 min (14). After filtration, extracts were evaporated to dryness in vacuo at $40^{\circ} \mathrm{C}$ to avoid any loss or degradation of fruit constituents. Extraction yield $(\%, w / w)$, was expressed as the amount of dry extract obtained from $100 \mathrm{~g}$ of the fresh plant material (fw). Measurements of refractive index, relative density and $\mathrm{pH}$ values were based on the official procedures explained in the European Pharmacopoeia $9^{\text {th }}$ edition (15).

\section{Polyphenolics content}

Total phenolic content (TPC) of fruit extracts was measured by the modified Folin-Ciocalteu (FC) colorimetric method (16). Briefly, $50 \mu \mathrm{L}$ of each extract solution was mixed with $250 \mu \mathrm{L}$ of $\mathrm{FC}$ reagent. The mixture was vortexed for $1 \mathrm{~min}$, then $750 \mu \mathrm{L}$ of $20 \%$ aqueous sodium carbonate solution was added and the volume was made up to $5.0 \mathrm{~mL}$ with distilled water. After $2 \mathrm{~h}$ of incubation at room temperature, the absorbance was measured at $760 \mathrm{~nm}$. A calibration curve was constructed using gallic acid standard solutions $(0.015 \mathrm{mg} / \mathrm{mL}$ to 0.150 $\mathrm{mg} / \mathrm{mL}$ ). The results were expressed as $\mathrm{mg}$ of gallic acid equivalents (GAE) per $g$ of dry plant material weight (dw). 
Total flavonoid content (TFC) was assayed by the aluminum chloride colorimetric method (17), with minor modifications. Briefly, a volume of 0.5 $\mathrm{mL}$ of extracts or standard solutions were mixed with $1.5 \mathrm{~mL}$ of methanol, $100 \mu \mathrm{L}$ of $10 \%(\mathrm{w} / \mathrm{v})$ aluminum chloride solution, $100 \mu \mathrm{L}$ of potassium acetate solution $(1.0 \mathrm{M})$ and $2.8 \mathrm{~mL}$ of distilled water. The mixture was incubated at room temperature for $30 \mathrm{~min}$ and the absorbance was measured at $425 \mathrm{~nm}$. Rutin solutions $(0.05-0.50 \mathrm{mg} / \mathrm{mL})$ were used for the construction of the standard curve. The results were expressed as $\mathrm{mg}$ of rutin equivalents (RE) per g of dw.

Determination of proanthocyanidins was based on the vanillin assay (18). The absorbance was measured at $500 \mathrm{~nm}$. A standard curve was constructed using catechin solutions (0.03-0.30 $\mathrm{mg} / \mathrm{mL}$ ). The total content of proanthocyanidin (TPAC) was expressed as mg of catechin equivalent (CE) per g of dry plant material weight (dw). The official methods from the European Pharmacopoeia $9^{\text {th }}$ edition (15) were used for determination of total tannins (TTC) and anthocyanins content (TAC) in the examined fruit extracts. The tannin content (TC) was expressed as pyrogallol (\%). Anthocyanins concentration was expressed as mg cyanidin-3-glucoside chloride (CG) per $100 \mathrm{~g}$ of dw.

\section{Tyrosinase inhibitory activity assay}

The bioassay of the tyrosinase inhibitory activity (TIA) was performed as previously described (19), with some modifications. Mushroom tyrosinase was used, with L-DOPA as the substrate. First, $40 \mu \mathrm{L}$ of $10 \mathrm{mM}$ L-DOPA and $100 \mu \mathrm{L}$ of $50 \mathrm{mM}$ sodium phosphate buffer ( $\mathrm{pH}$ 6.8) were inserted in a 96-well plate and incubated at $30^{\circ} \mathrm{C}$ for $5 \mathrm{~min}$. Then, $100 \mu \mathrm{L}$ of extracts dissolved in DMSO, followed by $30 \mu \mathrm{L}$ of the aqueous solution of mushroom tyrosinase $(217$ units $/ \mathrm{mL})$ were added to the mixture and incubated at $30^{\circ} \mathrm{C}$ for $25 \mathrm{~min}$. Enzymatic activity was quantified by measuring the absorbance at $475 \mathrm{~nm}$. Negative controls, without inhibitor, but containing 3.3\% DMSO were also determined. The percentage of tyrosinase activity was obtained by equation 1:

$$
\text { Activity }(\%)=\frac{\text { Acontrol }- \text { Asample }}{\text { Acontrol }} \times 100
$$

\section{Antioxidant activity assays}

The DPPH scavenging assay was done according to the method reported by Brand-Williams et al. (20), with some modifications. Briefly, an aliquot of the various concentrations of extracts $(100 \mu \mathrm{L})$ was mixed with $2.9 \mathrm{~mL}$ of methanol and $1.0 \mathrm{~mL}$ of fresh- ly prepared DPPH working solution (90 $\mu \mathrm{mol} / \mathrm{L})$. The colorimetric decrease in absorbance was measured at $517 \mathrm{~nm}$. The radical scavenging activity was calculated using equation 1 .

Nitric oxide radical scavenging activity (NO) was measured according to the modified method described by Sreejayan and Rao (21). About $1 \mathrm{~mL}$ of sodium nitroprusside $(10 \mathrm{mM})$ in the phosphate buffer (0.1 M, pH 7.4) was mixed with different concentrations of extract or standard solutions in the phosphate buffer. After incubation at $25^{\circ} \mathrm{C}$ for 120 min, $0.5 \mathrm{~mL}$ of the mixture was pipetted and $0.5 \mathrm{~mL}$ of Griess reagent was added. The absorbance was measured at $546 \mathrm{~nm}$. The percentage of NO scavenging activity was calculated using the equation 1 . The ability of extracts to inhibit non-site-specific hydroxyl radical scavenging activity $(\cdot \mathrm{OH}-\mathrm{NS})$ was estimated according to the method of Halliwell et al. (22), with some changes. The reaction mixture contained $100 \mu \mathrm{L}$ of extract or standard at various concentrations, $500 \mu \mathrm{L}$ of 2-deoxy-D-ribose $(5.6 \mathrm{mM})$ in phosphate buffer (50 mM, pH 7.4), $200 \mu \mathrm{L}$ of premixed solution of $100 \mu \mathrm{M} \mathrm{FeCl}_{3}$ and $104 \mu \mathrm{M}$ EDTA ( $1: 1 \mathrm{v} / \mathrm{v}), 100 \mu \mathrm{L}$ of $\mathrm{H}_{2} \mathrm{O}_{2}(1.0 \mathrm{mM})$ and $100 \mu \mathrm{L}$ of L-ascorbic acid $(1.0 \mathrm{mM})$. After incubation at $50^{\circ} \mathrm{C}$ for $30 \mathrm{~min}, 1 \mathrm{~mL}$ of $2.8 \% \mathrm{TCA}$ and $1 \mathrm{~mL}$ of $1.0 \%$ TBA were added, the mixture was incubated and the absorbance was measured at $532 \mathrm{~nm}$. The ability of extracts to inhibit site-specific hydroxyl radical scavenging activity $(\cdot \mathrm{OH}-\mathrm{SS})$ was estimated according to the procedure for the $(\cdot \mathrm{OH}-\mathrm{NS})$ assay, except that EDTA was replaced by the phosphate buffer (23). The percentage of $\cdot \mathrm{OH}$ scavenging activity was calculated using equation 1 .

The ferric reducing antioxidant power (FRAP) assay was used to estimate the total antioxidant activity of the examined extracts (24). The FRAP reagent was freshly prepared by mixing $300 \mathrm{mM}$ acetate buffer $\mathrm{pH} 3.6,10 \mathrm{mM}$ TPTZ solution in 40 $\mathrm{mM} \mathrm{HCl}$ and $20 \mathrm{mM} \mathrm{FeCl}_{3} \times 6 \mathrm{H}_{2} \mathrm{O}$ solution $(10: 1$ $: 1, \mathrm{v} / \mathrm{v} / \mathrm{v})$. An aliquot of $100 \mu \mathrm{L}$ of extract solution was mixed with $3.0 \mathrm{~mL}$ of FRAP reagent. The absorbance readings were taken at $593 \mathrm{~nm}$, after 10 min of incubation at room temperature. Aqueous solutions of $\mathrm{FeSO}_{4} \times 7 \mathrm{H}_{2} \mathrm{O}(100-1000 \mu \mathrm{M})$ were used for calibration. The FRAP value was expressed as $\mu \mathrm{mol} \mathrm{Fe}^{2+}$ equivalents per $\mathrm{g}$ of $\mathrm{dw}$.

The inhibition of $\beta$-carotene bleaching (BCB) was evaluated by the modified $\beta$-carotene linoleate model (25). Shortly, $1 \mathrm{~mL}$ of $\beta$-carotene solution in chloroform $(0.2 \mathrm{mg} / \mathrm{mL}), 25 \mu \mathrm{L}$ of linoleic acid and $200 \mathrm{mg}$ of Tween 20 emulsifier were transferred to a round-bottomed flask. The chloroform was then evaporated under a nitrogen stream. Oxygenated 
water $(50 \mathrm{~mL})$ was added into the flask and shaken vigorously. Further, $200 \mu \mathrm{L}$ of the $\beta$-carotene-linoleic acid emulsion was added to the $25 \mu \mathrm{L}$ of extracts in each well. The plates were shaken at $300 \mathrm{rpm}$ for $5 \mathrm{~min}$ and incubated at $55^{\circ} \mathrm{C}$. The absorbance was read at $450 \mathrm{~nm}$. BCB inhibition was calculated according to the equations 2 and 3 ,

$$
\begin{aligned}
\text { Inhibition }(\%) & =\frac{\text { Rcontrol }- \text { Rsample }}{\text { Rcontrol }} \times 100 \\
\mathrm{R} & =\frac{\ln \left[\mathrm{At}_{0} / \mathrm{At}_{120}\right]}{120}
\end{aligned}
$$

where $\mathrm{R}=$ bleaching rate; $\mathrm{ln}=$ natural $\log ; \mathrm{At}_{0}=$ the initial absorbance measured at $\mathrm{t}=0 \mathrm{~min}$ and $\mathrm{At}_{120}=$ the absorbance measured at $\mathrm{t}=120 \mathrm{~min}$.

The ferrous ion-chelating activity (FIA) was estimated according to the method described by Dinis et al. (26), with some modifications. Briefly, an aliquot $(150 \mu \mathrm{L})$ of extracts was mixed with 50 $\mu \mathrm{L}$ of $\mathrm{FeSO}_{4} \times 7 \mathrm{H}_{2} \mathrm{O}(2.0 \mathrm{mM})$ in a 96-well plate and incubated for $5 \mathrm{~min}$ at room temperature. The reaction was initiated by the addition of $50 \mu \mathrm{L}$ of ferrozine $(5.0 \mathrm{mM})$. The reaction mixture was shaken vigorously and left to stand at room temperature for $10 \mathrm{~min}$ and the absorbance was measured at $562 \mathrm{~nm}$. FIA was calculated using equation 1 .

\section{Statistical analysis}

Data of all measurements obtained in triplicate are presented as mean values \pm standard deviation. All statistical analyses were performed using Microsoft Excel 2007 and SPSS (version 25.0). The analysis of variance (ANOVA) was followed by Tukey's test for the determination of significant dif- ferences. The principal component analysis (PCA) was performed to analyse the correlation between different activities of the fruit extracts and their polyphenolic composition. Pearson's correlation coefficients (r) were used to determine the relationship between the measured variables. Levels of $p<0.05$ or $p<0.01$ were used as the criterion for statistical significance.

\section{RESULTS AND DISCUSSION}

\section{Extraction yields and physicochemical properties of the extracts}

Besides the extraction method, the type of solvent had an essential effect on the extracts' quality and quantity. The yields reported for ultrasonic extraction and the physicochemical properties of the extracts are given in Table 1. The ultrasonic extraction of $S$. aucuparia showed higher yields, while both plants extracted with propylene glycol-water $(45: 55, \mathrm{v} / \mathrm{v})$ resulted in the highest extraction yield. To the best of our knowledge, aqueous propylene glycol was not used for the extraction of $R$. canina and $S$. aucuparia fruits. The extraction yields for both plants were similar for MEs and EEs. The water extraction capacity was a little lower for obtaining $R$. canina extracts. Some non-phenolic compounds have better solubility in water and methanol (13). Accordingly, the higher extraction yield of $S$. aucuparia extracts can be explained by the presence of these compounds to a greater extent. To the best of our knowledge, there are no previous reports on physicochemical properties of the examined fruit extracts. WEs had significantly lower $\mathrm{pH}$

\begin{tabular}{|c|c|c|c|c|c|c|}
\hline Extract & $\begin{array}{c}\text { Plant } \\
\text { source }\end{array}$ & $\begin{array}{c}\text { Solvent } \\
\text { yield fw, \%\# }\end{array}$ & Extraction & $\begin{array}{c}\mathrm{pH} \\
\text { value }\end{array}$ & $\begin{array}{c}\text { Refractive } \\
\text { index }\end{array}$ & $\begin{array}{c}\text { Relative } \\
\text { density, } \mathrm{g} \mathrm{cm}^{-3} \\
\end{array}$ \\
\hline RCME & R. canina & methanol & $14.08 \pm 0.02^{\mathrm{a}}$ & $6.46 \pm 0.04^{\mathrm{a}}$ & $1.334 \pm 0.009^{\mathrm{a}}$ & $0.816 \pm 0.029^{a, b}$ \\
\hline RCEE & $R$. canina & $\begin{array}{l}\text { ethanol-water } \\
(7: 3, \mathrm{v} / \mathrm{v})\end{array}$ & $16.14 \pm 0.03^{b}$ & $5.32 \pm 0.03^{b}$ & $1.363 \pm 0.004^{\mathrm{b}}$ & $0.897 \pm 0.025^{\mathrm{b}}$ \\
\hline RCPE & R. canina & $\begin{array}{l}\text { propylene glycol- } \\
\text { water }(45: 55, \mathrm{v} / \mathrm{v})\end{array}$ & $32.48 \pm 0.06^{c}$ & $4.65 \pm 0.01^{\mathrm{c}}$ & $1.386 \pm 0.006^{\mathrm{c}}$ & $1.045 \pm 0.030^{c}$ \\
\hline RCWE & R. canina & water & $19.85 \pm 0.04^{\mathrm{d}}$ & $3.69 \pm 0.03^{\mathrm{d}}$ & $1.338 \pm 0.004^{\mathrm{a}}$ & $1.016 \pm 0.017^{\mathrm{c}}$ \\
\hline SAME & S. aucuparia & methanol & $26.73 \pm 0.03^{\mathrm{e}}$ & $6.42 \pm 0.04^{a}$ & $1.337 \pm 0.012^{\mathrm{a}}$ & $0.843 \pm 0.037^{\mathrm{a}, \mathrm{b}}$ \\
\hline SAEE & S. aucuparia & $\begin{array}{l}\text { ethanol-water } \\
(7: 3, \mathrm{v} / \mathrm{v})\end{array}$ & $25.13 \pm 0.04^{\mathrm{f}}$ & $5.29 \pm 0.03^{b}$ & $1.364 \pm 0.005^{\mathrm{b}}$ & $0.910 \pm 0.029^{\mathrm{b}}$ \\
\hline SAPE & S. aucuparia & $\begin{array}{c}\text { propylene glycol- } \\
\text { water }(45: 55, \mathrm{v} / \mathrm{v})\end{array}$ & $33.11 \pm 0.06^{\mathrm{g}}$ & $4.63 \pm 0.02^{c}$ & $1.381 \pm 0.004^{\mathrm{b}, \mathrm{c}}$ & $1.057 \pm 0.022^{\mathrm{c}}$ \\
\hline SAWE & S. aucuparia & water & $21.19 \pm 0.03^{\mathrm{h}}$ & $3.87 \pm 0.04^{\mathrm{e}}$ & $1.339 \pm 0.008^{\mathrm{a}}$ & $1.002 \pm 0.037^{\mathrm{c}}$ \\
\hline
\end{tabular}

Table 1. Extraction efficiency and physicochemical characterization of fruit extracts*.

$*$ The presented values are means \pm standard deviation $(n=3)$. In each column different letters mean significant differences $(\mathrm{p}<0.05)$;

${ }^{\#} \mathrm{fW}$ - calculated on the basis of fresh plant material weight 

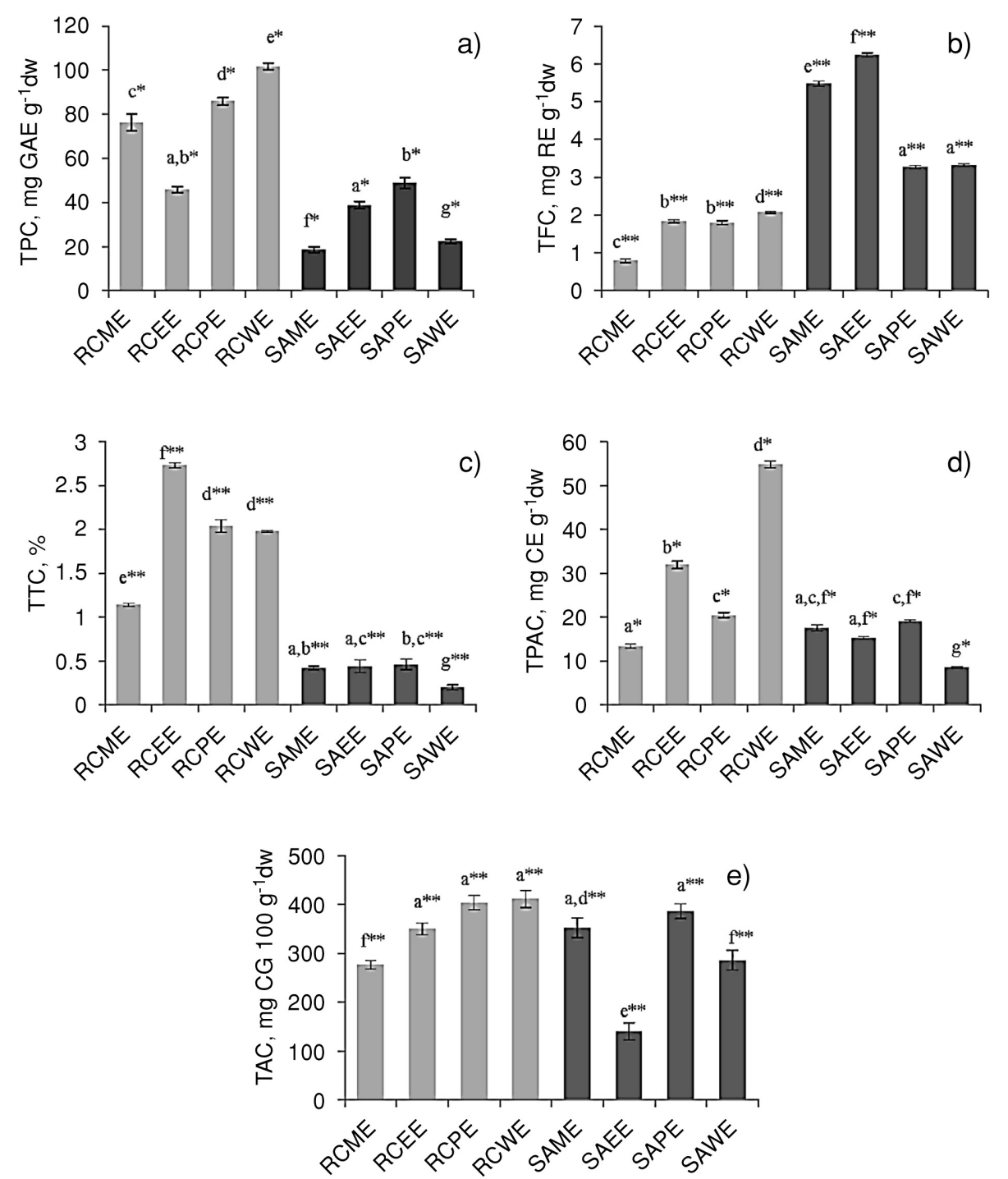

Figure 1. Polyphenolics content of fruit extracts. The results are expressed as means \pm standard deviation $(\mathrm{n}=3)$; TPC - total phenolic content; TFC - total flavonoid content; TTC, total tannin content; TPAC - total proanthocyanidin content; TAC - total anthocyanin content; GAE - gallic acid equivalents; RE - rutin equivalents; CE - catechin equivalents; CG - cyanidin-3-glucoside chloride; dw - calculated on the basis of dry plant material weight. Bars with the different lowercase letter are significantly different $\left({ }^{*} \mathrm{p}<0.05 ; * * \mathrm{p}<0.01\right)$

values compared to other extracts (nearly two times lower than MEs). RI and RD varied because different extraction solvents were used. PEs of $S$. aucuparia and $R$. canina had the highest RI and RD values, due to the propylene glycol-water $(45: 55, \mathrm{v} / \mathrm{v})$. The parameters tested are important for the standardization of the extracts, for the purpose of their controlled production and possible application in the pharmaceutical industry.

\section{Polyphenolics content}

The polyphenolics content of the examined fruit extracts is summarized in Figure 1. As we expected, TPC was dependent on the plant species and the extraction solvent as well (Fig. 1a). Higher TPC was observed for $R$. canina fruit extracts, where WE of R. canina showed the highest TPC. Previously reported TPC for the $R$. canina fruit extracts was $12.5-96.0 \mathrm{mg} \mathrm{GAE} \mathrm{g}^{-1}(8,27)$, which is in line with our findings. Higher TPC of $R$. canina WEs compared to MEs and EEs was confirmed by other authors $(28,29)$. Regarding $S$. aucuparia fruits, lower TPC values were reported in the literature, ranging from the 8.62 to $26.8 \mathrm{mg} \mathrm{GAE} \mathrm{g}^{-1}$ $(10,27,30)$. Unlike the $R$. canina extracts, EEs of $S$. aucuparia showed higher TPC compared to WEs. 
It is well-known that $\mathrm{FC}$ reaction is nonspecific to phenolic compounds, so a certain amount of nonphenolic substances may interfere with FC reagent, such as residual sugars, some inorganic substances, soluble proteins, organic acids $(27,31)$. Since the fruits contain a mixture of all these compounds, which contribute to the total phenolics, it was expected that the results of TPC assay would be different between the examined fruits and their extracts. TPC assay was applied with the aim to evaluate the content of a wide range of phenolic antioxidants, as bioactive substances, which might contribute to the total antioxidant activity and biological activity of fruit extracts.

Data showed variability in the TFC between the plants, as well as between the extracts (Fig. 1b). The higher TFC was obtained for $S$. aucuparia extracts. EEs and MEs of $S$. aucuparia had the greatest amount of flavonoids, nearly $70 \%$ and $86 \%$ higher amounts compared to EEs and MEs of $R$. canina, respectively. The contents of flavonoids in $R$. canina fruit extracts were higher than those reported by other researchers (28). Also, Kylli et al. (12) and Olszewska and Michel (10) measured lower TFC for $S$. aucuparia fruits. Flavonoid content in plant fruits can change according to the harvest time, climate factors and fruit ripeness (32).

To the authors' knowledge, no study has been made on TTC, TPAC and TAC in the examined fruits using techniques explained in the present study. As it can be seen in Figure 1c, $R$. canina extracts showed from 2.7 to 9.9 times higher levels of TTC in comparison with $S$. aucuparia extracts. For both plants, EEs and PEs showed a better selectivity for tannins extraction. It might be assumed that solvents methanol, ethanol-water $(7: 3, \mathrm{v} / \mathrm{v})$ and propylene glycol-water $(45: 55, \mathrm{v} / \mathrm{v})$ provided extraction of the similar amounts of tannins from the $S$. aucuparia fruits. The same applied to the PEs and WEs for the $R$. canina fruits. Previous studies were focused primarily on the content of ellagitannins in fruits (29, 33). However, Mikulic-Petkovsek et al. (11) reported very low TTC in $S$. aucuparia cultivar fruit extracts.

Data on the TPAC in extracts are presented in Figure 1d. The higher content was found in R. cani$n a$ fruits (WE and EE of $R$. canina), while propylene glycol-water $(45: 55, \mathrm{v} / \mathrm{v})$ extracted the most proanthocyanidins from $S$. aucuparia fruits. Taking into consideration the extracts preparation and the methodology described, present results for TPAC appeared to be higher than those from the literature $(10,29,30)$. According to the results presented in Figure 1e, fruits from both plants have a high amount of anthocyanins. Water and propylene glycol-water $(45: 55, \mathrm{v} / \mathrm{v})$ were found to be the most effective regarding the extraction of anthocyanins from the examined fruits. TAC in $R$. canina fruits was higher than that reported by Ganhao et al. (29). S. aucuparia extracts contained several times higher TAC than it was previously reported $(12,34)$.

Based on these analyses, the content of different classes of phenolic compounds in fruit extracts was strongly influenced by the extraction solvent. Although mixture propylene glycol-water (45: 55, $\mathrm{v} / \mathrm{v}$ ) has proved to be the most efficient regarding the extraction efficiency, however, the content of individual groups of compounds was not the highest in these extracts (extraction yield was related to various compounds present in the extracts, not only polyphenols). This highlighted the fact that there was no single extraction solvent that would isolate all the groups of phenolic compounds at the highest concentrations from the examined extract, which was demonstrated in our study.

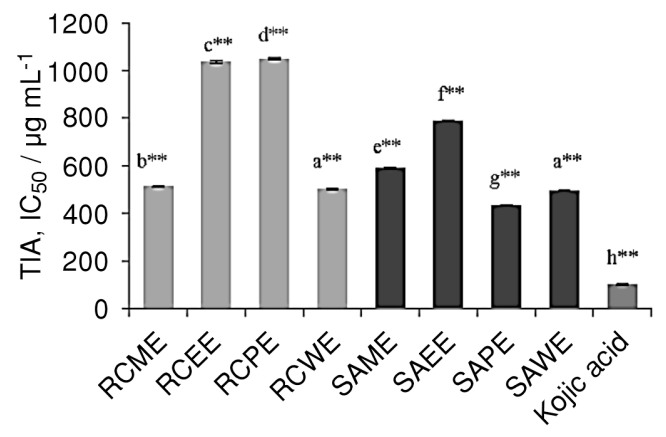

Figure 2. Tyrosinase inhibitory activity (TIA) of fruit extracts. The results are expressed as means \pm standard deviation $(\mathrm{n}=3)$. Bars with the different lowercase letter are significantly different $(* * \mathrm{p}<0.01)$. TIA-IC 50 is the concentration of extract inhibiting $50 \%$ of enzymatic activity 

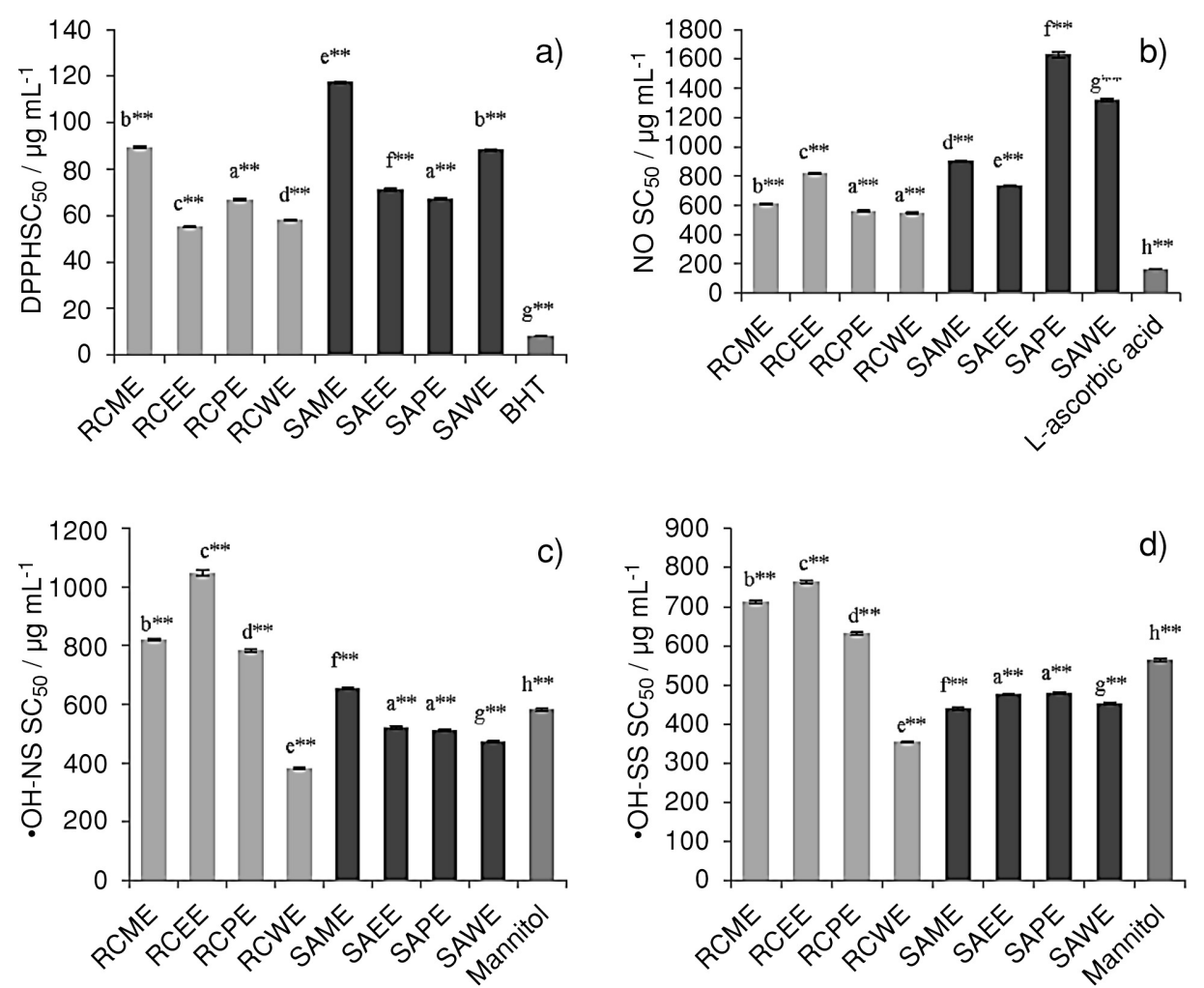

Figure 3. Antioxidant activity of fruit extracts against DPPH radical (a), scavenging of nitric oxide radicals (NO) (b), in non-site-specific (c) or site-specific (d) hydroxy radicals scavenging activity $(\bullet \mathrm{OH}-\mathrm{NS}$ and $\bullet \mathrm{OH}-\mathrm{SS}$, respectively). The results are expressed as means \pm standard deviation $(\mathrm{n}=3)$; dw - calculated on the basis of dry plant material weight. Bars with the different lowercase letter are significantly different $(* * \mathrm{p}<0.01) . \mathrm{SC}_{50}$ values are the concentrations of extract at which $50 \%$ of the free radicals were scavenged

\section{Tyrosinase inhibitory and antioxidant activity of} extracts

TIA of $R$. canina and $S$. aucuparia fruit extracts were examined for the first time in this report. The obtained results indicated $S$. aucuparia extracts had higher TIA than $R$. canina fruit extracts (Fig. 2). In comparison with an effective tyrosinase inhibitor, as a positive standard, PE of S. aucuparia and WEs from both plants revealed a considerable tyrosinase inhibitory potential. Our findings suggest that ultrasonic PEs of $S$. aucuparia and WEs of $R$. canina fruits might be effective for the inhibition of tyrosinase enzyme and treatment of skin hyperpigmentation and melanin-related disorders.

The antioxidant activity of fruit extracts is presented in Figures 3 and 4. All extracts demonstrated considerable DPPH radical scavenging activity (Fig. $3 \mathrm{a})$, especially EE, WE and PE of $R$. canina. Furthermore, S. aucuparia extracts were less effective than extracts from $R$. canina, using the same solvents for extraction. Regarding $R$. canina fruits, $\mathrm{DPPH} \mathrm{SC}_{50}$ values from the literature were higher and ranged from 278.9 to $750.0 \mu \mathrm{g} / \mathrm{mL}(6,7,35)$. Mrkonjić et al. (35) reported similar DPPH $\mathrm{SC}_{50}$ for WEs and MEs from $S$. aucuparia fruits. The other reports revealed lower DPPH scavenging activity of S. aucuparia fruit extracts $(9,10,30)$.

As it can be seen in Figure $3 \mathrm{~b}, R$. canina extracts showed better activity in reducing the generation of nitric oxide radicals, especially WEs and PEs. S. aucuparia EE had the highest activity among the $S$. aucuparia extracts (2.22 times higher than $\mathrm{PE})$. Literature data related to this assay for both plants are very scarce and reduced only to a few studies $(28,36)$.

$\cdot \mathrm{OH}-\mathrm{NS}$ and $\cdot \mathrm{OH}-\mathrm{SS}$ assays results are presented in Figures $3 \mathrm{c}$ and $3 \mathrm{~d}$. $R$. canina WEs showed a better activity for neutralization of hydroxyl radicals, with the lowest $\mathrm{SC}_{50}$ in both tests. Scavenging activities of $S$. aucuparia extracts were comparable and even higher than the activity of mannitol. WE of $R$. canina showed higher $\cdot \mathrm{OH}$ scavenging activity compared to mannitol. Reported $\mathrm{IC}_{50}$ values for $R$. canina fruit extracts were within the range of 
$119-1480 \mu \mathrm{g} / \mathrm{mL}$ and for $S$. aucuparia fruits 160-240 $\mu \mathrm{g} / \mathrm{mL}(28,36)$. To the best of our knowledge, there are no reports in the literature on $\cdot \mathrm{OH}-\mathrm{SS} \mathrm{SC}_{50}$ for the examined fruits/extracts. $\cdot \mathrm{OH}-\mathrm{NS}$ and $\cdot \mathrm{OH}-\mathrm{SS}$ assays served to explain possible different antioxidant mechanisms of the extracts. In the $\cdot \mathrm{OH}-\mathrm{NS}$ assay, EDTA forms a complex with $\mathrm{Fe}^{3+}$ ions and the antioxidant activity is demonstrated by neutralization of the already formed hydroxyl radicals. In the second case, the extracts may influence hydroxyl radical generation by $\mathrm{Fe}^{3+}$ ions complexion mechanism. Since all the extracts from this study exhibited higher activity in $\cdot \mathrm{OH}-\mathrm{SS}$ assay, they were also supposed to have a considerable iron chelating activity.

FRAP results of the examined extracts are shown in Figure 4a. The highest activity was calculated for WE of $R$. canina. According to the literature data, the antioxidant power of $R$. canina fruit extract was similar and amounted to $1043.5 \mu \mathrm{mol} / \mathrm{g}$
(37). In the study of Olszewska and Michel (10) the antioxidant power of $S$. aucuparia fruit extract was $441.5 \mu \mathrm{mol} / \mathrm{g}$, which is in line with our results.

The BCB assay showed that the analyzed extracts inhibited the oxidation of linoleic acid (Fig. $4 \mathrm{~b})$. The fruit extracts of $R$. canina demonstrated a higher inhibition of BCB compared to $S$. aucuparia extracts. The results were in accordance with the previous reports, where $\mathrm{IC}_{50}$ for $R$. canina fruits was $396.06 \mu \mathrm{g} / \mathrm{mL}$ (35). Regarding $S$. aucuparia fruit extracts, there is a lack of data concerning this method of determining antioxidant activity.

The present study demonstrated for the first time FIC capacity of the examined extracts in regard to ferrous ions (Fig. 4c). Chelating capacity can be also considered as part of antioxidant activity because chelation of metal ions can contribute to the prevention of free radicals formations (38). Even though the fruit extracts were not as strong chelators as a positive control, they exhibited moderate FIC a)

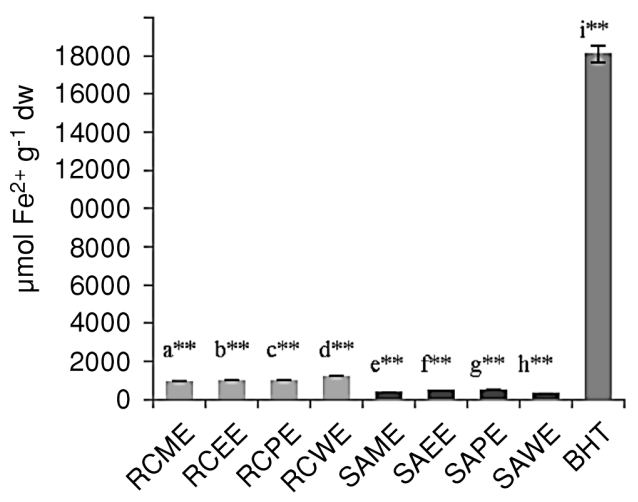

b)

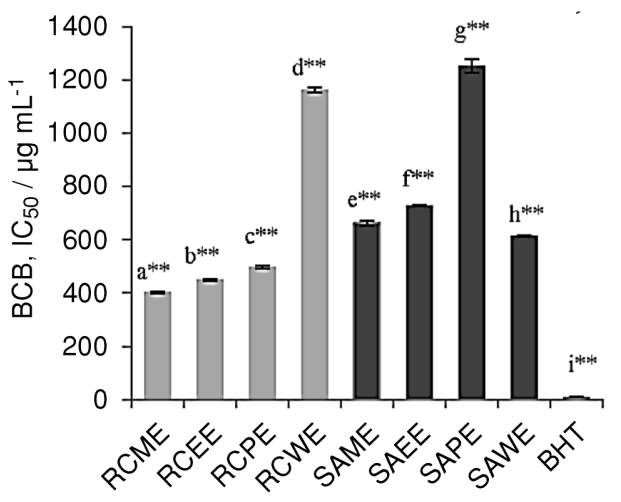

c)

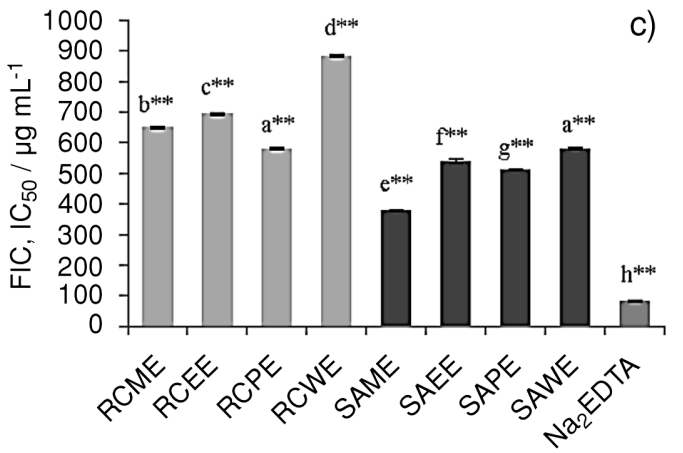

Figure 4. Antioxidant activity of fruit extracts: (a) ferric reducing antioxidant power (FRAP), (b) $\beta$-carotene bleaching assay (BCB) and (c) ferrous ion chelating activity (FIC). The results are expressed as means \pm standard deviation $(\mathrm{n}=3)$; $\mathrm{dw}-$ calculated on the basis of dry plant material weight. Bars with the different lowercase letter are significantly different $(* * \mathrm{p}<0.01)$. $\mathrm{FIC} \mathrm{IC}_{50}$ is the concentration of extract at which $50 \%$ of the metal ions were chelated, while $\mathrm{BCB}-\mathrm{IC}_{50}$ is the concentration of extract providing $50 \%$ of $\beta$-carotene bleaching 


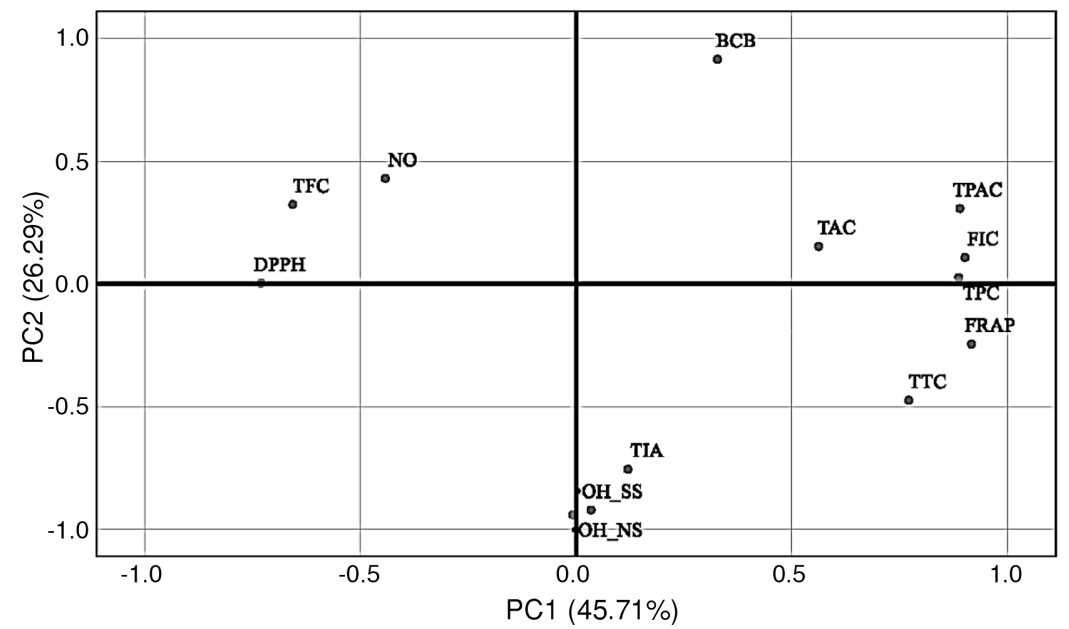

Figure 5. Principal component loadings plot from polyphenolic compounds, tyrosinase inhibitory and antioxidant properties of fruit extracts. Abbreviations: TPC - phenolic content; TFC - flavonoid content; TTC - tannin content; TPAC: proanthocyanidin content; AC anthocyanin content; TIA - tyrosinase inhibitory activity; DPPH - DPPH radical; NO - nitric oxide radical; hydroxy radical, $\bullet$ OH-NS non-site and $\bullet \mathrm{OH}-\mathrm{SS}$ - site-specific scavenging activity; FRAP - ferric reducing antioxidant power; $\mathrm{BCB}-\beta$-carotene bleaching assay; FIC - ferrous ion-chelating activity

values. S. aucuparia fruit extracts showed a higher FIC capacity, especially ME of $S$. aucuparia.

A direct comparison of the obtained results with literature data is not sometimes straightforward, considering the variety of the methods of extraction, differences in extraction solvents, nonstandardized methods of analysis and maturity stage of plant samples.

Polyphenols and other phytochemicals from the fruits have health-promoting effects when used as functional food or pharmaceutical preparations (39-41). The body absorption of phenolic compounds depends on their bioavailability. Glycosylated forms and polyphenol mixtures are generally absorbed in the intestine. Some molecules have a higher absorption efficiency than others, such as gallic acid and isoflavones, then a little lower catechins and quercetin glycosides, followed by proanthocyanidins and anthocyanins (42). Bioavailability might be increased by the encapsulation of extract into liposomes, nanoemulsions or cyclodextrins (43). Our study emphasizes the importance of knowing the natural polyphenols content present in the examined fruit extracts, as antioxidants and antityrosinase agents. Future research should be focused on their bioavailability and in vivo physiological effects, cell proliferation, and cytotoxicity assays and their role in human health.

\section{Principal component and correlation analyses}

The PCA (Fig. 5) resulted in a two-component model that explained $72 \%$ of the total variance. The first principal component (PC1) accounted for $45.71 \%$ and the second component (PC2) for $26.29 \%$ of the total variance in the data set. According to the loadings plot, it was noted that $\cdot \mathrm{OH}$ scavenging activity and TIA had low, but similar loading on PC1, indicating that assays were highly correlated among each other. It was observed that the extracts containing high levels of polyphenols (WEs and PEs) were also potent radicals' scavengers, suggesting that polyphenols may be the main components responsible for the antioxidant properties of extracts. In accordance to that, a significant correlation was noticed between TPC, TTC, TPAC and DPPH assay $(r=-0.608, r=-0.643$ and $\mathrm{r}=-0.56$, respectively; $\mathrm{p}<0.01$ ); as well as between TPC, TTC and NO scavenging activity $(r=-0.548$ and $\mathrm{r}=-0.575, \mathrm{p}<0.01$, respectively). It is worth pointing that TFC contributed mostly to the FIC ( $\mathrm{r}=$ $-0.628, \mathrm{p}<0.01)$ and $\cdot \mathrm{OH}$ scavenging activity $(\mathrm{r}=$ $-0.424, \mathrm{p}<0.05$ for $\cdot \mathrm{OH}-\mathrm{NS}$ and $\mathrm{r}=-0.557, \mathrm{p}<$ 0.01 for $\cdot \mathrm{OH}-\mathrm{SS})$. PC2 explained the variation between the extracts regarding TPAC, TAC and $\mathrm{BCB}, \mathrm{NO}$ and DPPH scavenging assays. TPAC and TAC especially contributed to DPPH activity. However, tannins were the main contributors to NO scavenging activity of the extracts. The present study reported the lack of correlation between TPC and $\mathrm{BCB}$ assay, which was in accordance with other researchers (44). The content of proanthocyanidins showed the highest correlation related to BCB assay $(r=0.455, p<0.05)$. There was a moderate correlation between TIA and $\cdot \mathrm{OH} \_\mathrm{NS}(\mathrm{r}=0.676)$, as well 
as $\cdot O H \_S S$ activity $(r=0.594)$, with a statistical significance of $\mathrm{p}<0.01$.

\section{CONCLUSION}

In summary, the polyphenols analysis of extracts has shown the high contents of biologically active compounds that gave a contribution to the examined bioactivities of the extracts. The polyphenols content evaluation of the ultrasonic extracts from $S$. aucuparia and $R$. canina fruits with different solvents showed water to be the best for a thorough extraction of the bioactive compounds from the $R$. canina fruits, while propylene glycol-water (45: 55 , $\mathrm{v} / \mathrm{v})$ was the most efficient regarding $S$. aucuparia fruits, followed by ethanol-water $(7: 3, \mathrm{v} / \mathrm{v}) . R$. canina WEs and PEs showed higher antioxidant activity, including scavenging activity of different free radicals. However, S. aucuparia ultrasonic PEs demonstrated a higher potential concerning tyrosinase inhibitory and chelating activity. Therefore, since they represent great sources of natural antityrosinase inhibitors and antioxidants, these ultrasonic extracts can be considered as promising candidates suitable for the application in the pharmaceutical industry, for oxidative stress prevention or treatment of skin hyperpigmentation and melaninrelated disorders.

\section{Acknowledgments}

This work was supported by the Ministry of Education, Science and Technological Development of the Republic of Serbia (project number III 45017).

\section{REFERENCES}

1. Nile S.H., Park S.W.: Nutrition 30, 134 (2014).

2. Szajdek A., Borowska E.J.: Plant Foods Hum. Nutr. 63, 147 (2008).

3. Maisuthisakul P., Gordon M.H.: Food Chem. 117, 332 (2009).

4. Ebanks J.P., Wickett R.R., Boissy R.E.: Int. J. Mol. Sci.10, 4066 (2009).

5. Bošnjaković D., Ognjanov V., Ljubojević M., Barać G. et al.: Genetika 44, 81 (2012).

6. Barros L., Carvalho A.M., Ferreira I.C.F.R.: Food Res. Int. 44, 2233 (2011).

7. Demir N., Yildiz O., Alpaslan M., Hayaloglu A.A.: LWT - Food Sci. Technol. 57, 126 (2014).

8. Ercisli S.: Food Chem. 104, 1379 (2007).

9. Aladedunye F., Matthäus B.: Food Chem. 159, 273 (2014).
10. Olszewska M.A., Michel P.: Nat. Prod. Res. 23, 1507 (2009).

11. Mikulic-Petkovsek M., Krska B., Kiprovski B., Veberic R.: J. Food Sci. 82, 647 (2017).

12. Kylli P., Nohynek L., Puupponen-Pimia R., Westerlund-Wikstrom B., McDougall D. et al.: J. Agric. Food Chem. 58, 11985 (2010).

13. Do Q.D., Angkawijaya A.E., Tran-Nguyen P.L., Huynh L.H., Soetaredjo F.E. et al.: J. Food Drug. Anal. 22, 296 (2014).

14. Khan M.K., Abert-Vian M., Fabiano-Tixier A.S., Dangles O., Chemat F.: Food Chem. 119, 851 (2010).

15. European Pharmacopoeia Commission, European Pharmacopoeia, $9^{\text {th }}$ ed., Council of Europe, Strasbourg, 2017.

16. Singleton V.L., Orthofer R., Lamuela-Raventos R.M.: Methods Enzymol. 299, 152 (1999).

17. Woisky R.G., Salatino A.: J. Apic. Res. 37, 99 (1998).

18. Price M.L., Van Scoyoc S., Butler L.G.: J. Agric. Food Chem. 26, 1214 (1978).

19. Fu B., Li H., Wang X., Lee F.S.C., Cui S.: J. Agric. Food Chem. 53, 7408 (2005).

20. Brand-Williams W., Cuvelier M.E., Berset C.: LWT - Food Sci. Technol. 28, 25 (1995).

21. Sreejayan N., Rao M.N.: J. Pharm. Pharmacol. 49, 105 (1997).

22. Halliwell B., Gutteridge J.M.C., Aruoma O.I.: Anal. Biochem. 165, 215 (1987).

23. Aruoma O.I., Grootveld M., Halliwell B.: J. Inorg. Biochem. 29, 289 (1987).

24. Benzie I.F.F., Strain J.J.: Anal. Biochem. 239, 70 (1996).

25. Koleva I.I., Beek T.A., Linssen J.P.H., Groot A., Evstatieva L.N.: Phytochem. Anal. 13, 8 (2002).

26. Dinis T.C.P., Madeira V.M.C., Almeida L.M.: Arch. Biochem. Biophys. 315, 161 (1994).

27. Kahkonen M.P., Hopia A.I., Vuorela H.J., Rauha J.P., Pihlaja K. et al.: J. Agric. Food Chem. 47, 3954 (1999).

28. Nađpal J.D., Lesjak M.M., Šibul F.S., Anačkov G.T., Četojević-Simin D.D. et al.: Food Chem. 192, 907 (2016).

29. Ganhao R., Estevez M., Kylli P., Heinonen M., Morcuende D.: J. Agric. Food Chem. 58, 8854 (2010).

30. Šavikin K.P., Zdunić G.M., Krstić-Milošević D.B., Šircelj H.J., Stešević D.D., Pljevljakušić D.S.: Chem. Biodivers. 14, e1700329 (2017).

31. Prior R.L., Wu X., Schaich K.: J. Agric. Food Chem. 53, 4290 (2005).

32. Elmastas M., Demir A., Genc N., Dolek U., Gunes M.: Food Chem. 235, 154 (2017). 
33. Fecka I.: Phytochem. Anal. 20, 177 (2009).

34. Koponen J.M., Happonen A.M., Mattila P.H., Törrönen A.R.: J. Agric. Food Chem. 55, 1612 (2007).

35. Barros L., Carvalho A.M., Morais J.S., Ferreira I.C.F.R.: Food Chem. 120, 247 (2010).

36. Mrkonjić Z.O., Naðpal J.D., Beara I.N., Aleksić Sabo V.S., Četojević-Simin D.D. et al.: J. Serb. Chem. Soc. 82, 651 (2017).

37. Gao X., Bjork L., Trajkovski V., Uggla M.: J. Sci. Food Agric. 80, 2021 (2000).

38. Gutierrez R.M.P., Ahuatzi D.M.: J. Nutr. Food Sci. 5, 376 (2015).

39. Patel S.: Trends Food Sci. Technol. 63, 29 (2017).
40. Fattahi A., Niyazi F., Shahbazi B., Farzaei M.H., Bahrami G.: J. Evidence-Based Complement. Altern. Med. 22, 127 (2016).

41. Jiménez S., Jiménez-Moreno N., Luquin A., Laguna M., Rodríguez-Yoldi M.J., AncínAzpilicueta C.: Food Addit. Contam. Part A 34, 1121 (2017).

42. Lima G.P.P., Vianello F., Corręa C.R., Campos R.A.S., Borguini M.G.: Food Nutr. Sci. 5, 1065 (2014).

43. Mignet N., Seguin J., Chabot G.: Pharmaceutics 5, 457 (2013).

44. O’Sullivan A.M., O'Callaghan Y.C., O'Grady M.N., Queguineur B. et al.: Food Chem. 126, 1064 (2011).

Received: 8.11.2018 